\title{
Link between enteroviruses and dilated cardiomyopathy: serological and molecular data
}

\author{
P J Keeling, S Tracy
}

The involvement of enteroviruses in the aetiology of dilated cardiomyopathy (DCM) remains controversial in clinical cardiology as well as in virology. Though many acute viral infections are accompanied by clinical or electrocardiographic evidence of cardiac involvement $^{1}$ it is difficult to prove causation. Enteroviruses have been isolated from the myocardium of patients with fulminant acute myocarditis, ${ }^{2}$ but not from those with DCM. Accumulated evidence suggests that enteroviruses, and in particular coxsackie $B$ viruses (CVBs), are the most common cause of acute myocarditis and pericarditis. ${ }^{3-5}$ In 1964 Burch suggested that acute viral myocarditis may presage DCM. ${ }^{6}$ Conventional virological techniques, however, have consistently failed to detect infectious virus in samples of myocardium from patients with DCM. The principal supporting evidence linking enterovirus infection to the development of DCM is indirect and is based upon retrospective serological studies and prospective follow up of patients after acute myocarditis. The recent development of nucleic acid hybridisation techniques for the detection of enteroviral genomes within myocardial tissue has provided the first direct evidence of enteroviral involvement in human DCM. None the less, the relation between the presence of enteroviral genome within the myocardium of patients with DCM and the aetiology of the disease remains ill-defined, as does the clinical diagnostic value of such findings. Here we will review key enteroviral serological and molecular findings and discuss what role enteroviruses may have in the pathogenesis of DCM.

\section{Clinical and serological data}

PROGRESSION FROM ACUTE MYOCARDITIS TO DCM Longitudinal studies support the concept that DCM may result from prior acute viral myocarditis (table 1).$^{7-15}$ One early report of 14 patients with suspected CVB-induced myo-pericarditis showed that all patients were left with chronic heart disease or symptoms: three patients developed chronic heart failure, two cardiomegaly, three chronic chest pain, and six had persistent electrocardiographic abnormalities. ${ }^{7}$ Another study of 42 patients presenting with clinical myocarditis and pericarditis reported that DCM developed in three $(7 \%)$ patients, and unexplained chronic heart failure developed in two others. ${ }^{8}$ Levi and colleagues have suggested that acute myocarditis associated with CVB infection is associated with a poorer long-term prognosis than idiopathic myocarditis. ${ }^{15}$ In their study of 68 patients presenting with clinical myocarditis, 10 of 42 patients who had complementfixing antibodies against CVBs developed DCM during a 15 year follow up. ${ }^{15}$ No longterm sequelae were seen in patients without these antibodies.

Clinical criteria are unreliable in the diagnosis of myocarditis ${ }^{16}{ }^{17}$ and not many patients with clinically suspected acute myocarditis have active inflammatory cell infiltration within the myocardium..$^{18}$ Few prospective studies have attempted to confirm the clinical suspicion of myocarditis by histopathological assessment of the myocardium. Billingham et al performed sequential endomyocardial biopsies on 20 patients with histopathologically confirmed myocarditis and showed that interstitial fibrosis developed in all patients within 1-12 months. ${ }^{13}$ In eight (40\%) patients, these changes were considered compatible with the morphological diagnosis of DCM and were accompanied by the development of clinical heart failure (indeed three patients required cardiac transplantation for end stage DCM). In another study, Quigley and colleagues reported that DCM developed over five years in $12(52 \%)$ of 23 patients with biopsy confirmed myocarditis. ${ }^{14}$

\section{RETROSPECTIVE SEROLOGICAL STUDIES}

Several retrospective serological studies have been performed in DCM (table 2). ${ }^{19-24}$ Despite the fact that patients with DCM usually present years after the development of cardiac symptoms, several studies showed raised titres of viral antibodies in patients with DCM. These were most commonly antibodies against enteroviruses. Kawai reported higher titres of complement-fixing antibodies to CVB and herpes simplex viruses, and neutralising antibodies to coxsackieviruses $\mathrm{B} 1$ and B3 in patients with DCM than in controls. ${ }^{20}$ 
Table 2 Enteroviral serology in DCM: retrospective studies

\begin{tabular}{|c|c|c|c|c|c|}
\hline Authors & Country & Assay & $\operatorname{DCM}(n(\%))$ & Controls (n (\%)) & $P$ \\
\hline $\begin{array}{l}\text { Fletcher, et al } 1968^{19} \\
\text { Kawai } 1971^{20} \\
\text { Falase, et al } 1979^{21} \\
\text { Cambridge, et al } 1979^{22} \\
\text { Kitaura } 1981^{23} \\
\text { Muir, et al } 1989^{24}\end{array}$ & $\begin{array}{l}\text { USA } \\
\text { Japan } \\
\text { Nigeria } \\
\text { UK } \\
\text { Japan } \\
\text { UK }\end{array}$ & $\begin{array}{l}\text { IgG } \\
\text { IgG } \\
\text { IgG } \\
\text { IgG } \\
\text { IgG } \\
\text { IgM }\end{array}$ & $\begin{array}{l}34(>30) \\
26(46) \\
44(72) \\
50(30) \\
63(42) \\
86(33)\end{array}$ & $\begin{array}{l}71(>30) \\
36(25) \\
52(52) \\
50(2) \\
63(24) \\
84(12)\end{array}$ & $\begin{array}{l}\text { NS } \\
<0.05 \\
<0.05 \\
<0.001 \\
<0.05 \\
<0.005\end{array}$ \\
\hline
\end{tabular}

Cambridge et al reported raised titres of neutralising antibodies to CVB in more patients with "congestive cardiomyopathy" than in controls with other cardiac diseases (15/50 $(30 \%) v 1 / 50(2 \%), \mathrm{P}<0.0005) .{ }^{22}$ High titres of neutralising antibodies were associated with a preceding flu-like illness and recent onset of symptoms. Whereas some have confirmed an association between virus specific IgG antibodies and $\mathrm{DCM}^{21} 23$ others have not. ${ }^{19}$

The discrepancies between results in these studies reflect not only methodological differences but also point out significant difficulties inherent in the diagnosis and assessment of patients with DCM. Firstly, strict diagnostic criteria have not always been applied and few patients in earlier studies had selective coronary arteriography and endomyocardial biopsy to exclude coronary artery disease, myocarditis, and specific heart muscle disease. Second, the control populations have varied in their "closeness" to the patients studied, with some controls sharing the same environment and being assessed at the same time as the patient, ${ }^{19}{ }^{23}$ whereas others were unrelated in time and place to the patient. ${ }^{20-22}$ When common and highly transmissible community infections such as those caused by enterovirus are evaluated, the degree of matching of patients and controls must be considered when enteroviral serology is interpreted. Unfortunately, the importance of this factor has been generally overlooked. Third, the evaluation of specific IgG antibodies against enteroviruses is limited by the fact that most adults will have already developed neutralising antibodies against a wide range of different enteroviral serotypes. These antibodies persist for years and their titres are continually boosted by exposure to the same viral serotype (homologous response) or to different enteroviruses (heterologous response). This makes it difficult to distinguish between recent and prior infection on the basis of a single raised neutralising antibody titre. Changing titres of such antibodies in sequential serum samples provide a more reliable method of identifying recent enteroviral infection, however, they are rarely seen. ${ }^{2022}$

The development and refinement of assays - capable of detecting virus-specific IgM rekindled interest in using enteroviral serology to substantiate the hypothesis of an enteroviral aetiology in DCM. Using a solid phase enzyme-linked immunosorbent assay (ELISA) that detects the common antigen in one of the enterovirus capsid proteins, VP1, Muir et al found that enteroviral IgM was more common in patients receiving cardiac transplants for end stage DCM than in healthy blood donors (28/86 (33\%) $v$ 10/84 (12\%), $\mathrm{P}<0.005) .{ }^{24}$

Radioimmunoassay techniques provide a more sensitive and specific method for the detection of CVB IgM. ${ }^{25}$ We used a reverse radioimmunoassay technique to detect virusspecific IgM in sera from 114 patients with DCM taken at the time of diagnosis or referral to our centre (Keeling et al, $\mathcal{F} \mathrm{Am}$ Coll Cardiol 1994;23:593-8). Included in this study were sera from 94 healthy unmatched controls, 41 age and sex matched controls from the patients' local community, and 32 members of their own household. All matched serum samples were obtained within two weeks of collection of serum from the patient. CVB IgM was more commonly detected in patients with DCM than unmatched controls (38 (33\%) v 5 (5\%), P = 3 $\times 10^{-7}$. When the data were compared with individually matched sera, however, there were no significant differences between patients and their community controls $(46 \% \vee 27 \%$, odds ratio $2 \cdot 4, \mathrm{P}=$ NS), or between patients and their household contacts $(37 \% \vee 28 \%$, odds ratio $1 \cdot 5, P=$ NS). Further analysis of the serological responses in these groups suggested cross infection with CVB between patients and environmental controls.

ENTEROVIRAL ANTIBODIES IN SEQUENTIAL SERA Muir et al also reported a persistent enteroviral IgM response in sequential serum samples from seven patients. ${ }^{24}$ They took this as evidence of persistent enteroviral infection. It is difficult to interpret these findings because only a few patients were studied, because it is not easy to distinguish between a persistent serological response and broadening of this response owing to re-infection, and because these patients were being treated with immunosuppressive drugs. We (Keeling et al, unpublished data) tested sequential serum samples taken from 65 patients with DCM for persistent virus-specific IgM. Eighteen of the 22 patients with CVB IgM at diagnosis rapidly lost it and specific IgM (>3 months) persisted in only four patients. During follow up, there were 41 episodes of seroconversion that were highly suggestive of recurrent acute infection. These infections were transient in all but one patient.

Accumulated evidence suggests that DCM develops in a significant proportion of patients after a clinically important episode of acute viral myocarditis. In each of the prospective studies discussed, patients had symptoms and often had severe myocardial dysfunction. Asymptomatic viral infection and myocarditis are common ${ }^{5}$ and it is not unreasonable to suggest that this population may be highly unrepresentative of myocarditis within the community. The use of more sensitive techniques to diagnose myocarditis ${ }^{26} 27$ and better assess viral involvement ${ }^{2829}$ may overcome some of these difficulties.

The finding of an association between enteroviral antibodies and DCM is consistent with persistent enteroviral infection in some patients. Although persistence of enteroviral 
antibodies in sera from patients with DCM is uncommon this does not exclude persistent infection within the heart. Enteroviruses undergo defective replication in which there is replication of viral genome within cardiomyocytes but no synthesis of structural proteins and no viral progeny. Defective replication interferes with cellular function and may be responsible for the development of clinical DCM. The introduction of molecular techniques for the identification of enteroviral genome within myocardial samples has allowed us further to assess enteroviral persistence.

\section{Molecular data}

NUCLEIC ACID HYBRIDISATION STUDIES

Nucleic acid hybridisation studies have provided the first direct evidence linking enteroviruses with human DCM. Because enteroviruses have a single-stranded RNA genome total ribonucleic acid (RNA) extracted from heart tissues is probed for enterovirus RNA sequences to determine whether an enterovirus infection is present or not. In a study that received much attention ${ }^{30}$ and in a subsequent paper ${ }^{31}$ Archard and colleagues probed RNA extracted from diseased human heart samples with deoxyribonucleic acid (DNA) or RNA sequences derived from the relatively well-conserved RNA polymerase coding sequence of the coxsackievirus B2 genome. They found that about $40-50 \%$ of cases of cardiomyopathy were positive by hybridisation for enterovirus RNA. It was unfortunate that these workers specifically implicated "coxsackieviruses" as the viruses detected because the techniques used were incapable of making this distinction; however, this oversight was corrected in later studies. Using a similar approach but with molecular probes derived from the well-characterised CVB3 genome, ${ }^{32} 33$ Wiegand et al showed enteroviral RNA in one of six explanted dilated cardiomyopathic hearts and none of eight normal control hearts. They used the RNA from the hearts as both a target for the probe and to generate a probe. ${ }^{34}$

In situ hybridisation is several orders of magnitude more sensitive than blot hybridisation approaches for the detection of gene sequences and can discern a single virusinfected cell in a field of uninfected cells. In this technique, thin tissue sections are permeabilised and then incubated in a mixture containing either DNA or RNA probes. Enteroviral probe sequences find and then hybridise with single-stranded RNA in the fixed cells, thus permitting the detection of cells infected with enterovirus. Several groups have shown enterovirus RNA in muscle cells of the myocardium in cases of DCM. In 1988 Easton and Eglin showed enteroviral sequences in diseased human myocardium. ${ }^{35}$ Kandolf and colleagues have been instrumental in presenting in situ hybridisation as a tool for the clinical diagnosis of enterovirus infections in diseased human heart. ${ }^{36}$ Using in situ hybridisation this group detected enterovirus RNA in $20-25 \%$ of dilated cardiomyopathic hearts but in none of the control hearts.

Current progress in molecular biological detection techniques means that there is no real advantage to using blot hybridisation to determine whether a heart sample is positive for enteroviral infection. Though it is not a rapid technique, in situ hybridisation has proved to be a valuable tool for the sensitive detection of enteroviruses in cardiac samples that provides simultaneous information about the pathological changes in the specific biopsy sample. ${ }^{3738}$ The polymerase chain reaction technique (discussed below), however, is more rapid, sensitive, and specific.

POLYMERASE CHAIN REACTION STUDIES

The polymerase chain reaction (PCR) has proved to be one of the most significant advances in molecular biology and its potential for answering questions in cardiology is still being explored. In this technique and specifically for the detection of enteroviral RNA, total heart RNA is transcribed with reverse transcriptase into complementary DNA (cDNA) copies. The cDNA sample is then subjected to repeated rounds of enzymatic amplification with a heat stable DNA polymerase that uses enterovirus-specific oligonucleotide primers to promote the amplification of a specific sequence from an enteroviral genome. ${ }^{39}$

One study using the PCR showed that five of 48 cases of myocarditis or DCM were positive for enterovirus RNA. ${ }^{40}$ Weiss and colleagues showed that one of five myocarditic heart samples was positive for enteroviral RNA but none of the $11 \mathrm{DCM}$ hearts was positive. ${ }^{41}$ This work was performed with primers designed to be specific for CVB3, which may have limited the scope of detection. Indeed subsequent work from this group showed five of $11 \mathrm{DCM}$ as well as nine of 24 hearts with various other conditions were positive for enteroviral RNA by PCR analysis. ${ }^{42}$ Three separate studies showed that nearly equivalent numbers of control hearts as well as dilated cardiomyopathic hearts were positive for the presence of enterovirus RNA in clinical specimens (table 3 ) ${ }^{43-45}$ Two independent studies ${ }^{4647}$ were unable to find enterovirus RNA in hearts of patients with DCM or in control hearts.

Cumulatively, while these results do not unequivocally support an enteroviral role in the aetiology of DCM, they tend to indicate such a role. This is consistent with the two other primary sources of data: human serological studies and murine models of enterovirus heart disease. None the less, several molecular studies have pointed out that many "control" hearts also have evidence of enteroviral infection. Again, these findings are consistent with both human serological and experimental murine data. Some possible reasons for these variant results are discussed below.

\section{Discussion}

It is likely that DCM is a heterogenous condition with different aetiologies operating in 
Table 3 Enteroviral nucleic acid hybridisation and PCR studies in DCM and myocarditis

\begin{tabular}{|c|c|c|c|c|}
\hline \multirow[b]{2}{*}{ Authors } & \multirow[b]{2}{*}{ Assay } & \multicolumn{3}{|c|}{ Enterovirus positive samples } \\
\hline & & $D C M(\%)$ & Myocarditis (\%) & Controls (\%) \\
\hline Bowles, et al $1989^{30}$ & Slot blot & $6 / 21(29)$ & & $1 / 19(5)$ \\
\hline Archard, et al $1991^{31}$ & Slot blot & $35 / 82(43)$ & $21 / 47(47)$ & $0 / 39(0)$ \\
\hline Wiegand, et al $1990^{34}$ & Slot blot & $1 / 6(17)$ & $0 / 8(0)$ & \\
\hline Easton and Eglin $1988^{35}$ & In situ & $6 / 13(46)$ & & \\
\hline Kandolf and Hofschneider $1989^{36}$ & In situ & $\begin{array}{r}8 / 47(17)^{\star} \\
10 / 33(30) \dagger\end{array}$ & & $0 / 53(0)$ \\
\hline $\begin{array}{l}\text { Jin, et al } 1990^{40} \\
\text { Weiss, et al } 1991^{41}\end{array}$ & PCR & $\begin{array}{l}3 / 20(15) \\
0 / 11(0)\end{array}$ & $\begin{array}{l}2 / 28(7) \\
1 / 5(20)\end{array}$ & $\begin{array}{l}0 / 9(0) \\
0 / 21(0)\end{array}$ \\
\hline Keeling, et al $1992^{43}$ & PCR & $6 / 50(12)$ & & $13 / 75(17)$ \\
\hline $\begin{array}{l}\text { Petitjean, et al } 1992^{44} \\
\text { Muir, et al } 1993^{45}\end{array}$ & $\begin{array}{l}\text { PCR } \\
\text { PCR }\end{array}$ & $\begin{array}{r}30 / 45(67) \\
4 / 18(22)\end{array}$ & $3 / 10(30)$ & $\begin{array}{r}25 / 50(50) \\
2 / 15(13)\end{array}$ \\
\hline Liljeqvist, et al $1993^{46}$ & PCR & $0 / 35(0)$ & & $0 / 15(0)$ \\
\hline Grasso, et al $1992^{47}$ & PCR & $0 / 21(0)$ & & $0 / 20(0)$ \\
\hline
\end{tabular}

different patients to produce the same clinical syndrome. Though there is clear experimental evidence implicating enterovirus in the pathogenesis of murine myocarditis and $\mathrm{DCM}^{13}$ the evidence in humans is less convincing. After an episode of acute viral myocarditis clinical DCM develops in some patients. Though enteroviral antibodies are more common in patients with DCM than in unmatched controls this is not the result of a persistent antibody response in these patients. The reason for this finding remains unclear.

Persistent enteroviral infection remains a major hypothesis for the pathogenesis of DCM. The results of molecular studies suggest that enteroviral genome is present in about $20-25 \%$ of hearts from patients with DCM and, though not discussed here, a similar proportion of patients with acute myocarditis. Variations between studies probably reflect different experimental techniques and technical details and differences in the groups studied and how DCM was diagnosed. The importance of these findings in general is that they extend earlier observations of enterovirus isolations from fulminant (often paediatric) myocarditis and lend support to Burch's hypothesis ${ }^{6}$ that in some patients viral myocarditis might precede DCM. Furthermore, these clinical data confirm and extend what we know from studies of cardiotropic enterovirus infections (such as CVB3) in murine models: that enteroviruses can cause both acute and chronic inflammatory heart disease. Whereas the data from many laboratories and clinical studies have shown a strong positive correlation between the presence of enterovirus RNA in cardiac muscle and acute or chronic inflammatory heart disease, questions that are particularly relevant to clinicians remain unanswered.

A curious observation that springs from a consideration of both the serological and molecular data is that enterovirus RNA has been found in normal hearts and in cardiac diseases other than DCM..$^{43-45}$ Do these results conflict with what has been seen in cases of acute fulminant myocarditis and in experimental murine models, data that strongly link enteroviruses to inflammatory heart disease? We suggest that the presence or absence of enteroviruses in the heart in itself is not the key criterion: the crux of the matter is how to distinguish between strains of cardiotropic enteroviruses that cause cardiac disease (cardiovirulent) and those that do not (avirulent strains). The CVBs are the human enteroviruses most often linked aetiologically to human inflammatory heart disease. It is clear from many murine studies that the CVBs are cardiotropic and that though not all CVBs are cardiovirulent, they replicate well in the murine heart. One may then offer an explanation for the finding of enteroviral RNA in many non-diseased hearts that is consistent with animal models of enteroviral heart disease-it is the predilection of cardiotropic human enteroviruses to replicate in the heart during an infection. If a cardiovirulent strain infects the heart, disease is likely to follow, whereas if the infection is caused by an avirulent strain no damage will occur. In either instance, however, the virus (cardiovirulent or not) would have been detectable in all of the studies to date. Because endomyocardial biopsy should not be undertaken lightly we shall have to accumulate data from many diseased as well as random and well-matched normal individuals over many years to answer this question finally and specifically.

We believe that the factor that will make the detection of enteroviruses in hearts crucial to clinical diagnoses will be the ability to distinguish between an infection caused by a cardiovirulent strain of enterovirus and an infection caused by a non-cardiovirulent strain. As discussed, results from murine models of CVB infection tell us that enteroviruses can replicate in hearts without causing detectable damage. Similarly, most naturally occurring infections with the related polioviruses go unnoticed and do not have clinical sequelae. Work from many laboratories has shown what determines the neurovirulent phenotype of polioviruses ${ }^{48}$ : this information is now being applied to the much studied cardiotropic coxsackievirus B3. ${ }^{49}$

We are still uncertain which enterovirus serotypes most often induce enteroviral heart disease. Much attention has been focused on the CVBs, but other enteroviruses have been isolated from heart muscle. To develop vaccines against the prime enterovirus causes of cardiac disease we must first know which they are. Molecular techniques will be needed to identify the aetiological viruses because it is so difficult to isolate infectious enteroviruses from dilated cardiomyopathic heart tissues.

The mechanism(s) by which enteroviruses induce cardiomyopathy are not clear. ${ }^{50}$ From experimental models of myocarditis and DCM we know that the cardiovirulent virus enters the cardiomyocyte: cardiomyocyte damage is clearly evident. Rapid destruction of the cardiomyocyte (in the case of acute viral myocarditis) or a longer term slowing of function in the infected cardiomyocyte (in chronic disease) are possibilities. We know from studies of picornaviruses in cell cultures, where specific cloned genes from the picornavirus genome have been expressed in cells, that such expression can be deleterious to the host cell. Immunological cross reactivity 
between viral and normal host proteins has been both postulated and, in some cases, demonstrated. It is possible that enteroviruses persist for long periods in the heart, although so far there is no rigorous proof of persistence. A combination of such mechanisms may be all that is necessary to make an acute infection in the heart progress slowly to cardiomyopathy and failure.

Over the past 20 years considerable evidence has accumulated both for and against a role for enterovirus in the pathogenesis of DCM. The jury is still out but most of the evidence from animal models and in humans, particularly that from the recent application of molecular techniques, supports an aetiological role for enteroviruses in DCM. Only by defining the mechanism(s) by which viruses induce acute and chronic heart disease can we hope to provide rational and effective treatment for viral myocarditis and DCM.

1 Woodruff JF. Viral myocarditis: A Review. Am $\mathcal{f}$ Pathol 1980;101:425-84.

2 Sutton G, Harding H, Truehart R, Clark H. Coxsackie B4 myocarditis in an adult: successful isolation of virus from myocarditis in an adult: successful isolation of virus f
ventricular myocardium. Aerosp Med 1967;38:66-9.

3 Reyes MP, Lerner AM. Coxsackievirus myocarditis- with special reference to acute and chronic effects. Prog Cardiovasc Dis 1985;27:373-94.

4 Grist NR. Coxsackie virus infections of the heart. In: Waterson AP, ed. Recent advances in clinical virology. London: Churchill Livingstone 1977;141-50.

5 Banatvala JE. Coxsackie $B$ virus infections in cardiac disease. In: Waterson AP, ed. Recent advances in clinical virology. London: Churchill Livingstone 1983; 99-117.

6 Burch GE, De Pasquale NP. Viral myocarditis. In: Cardiomyopathies. London: JA Churchill. 1964;99-115.

7 Sainani GS, Krompotic E, Slodki SJ. Adult heart disease due to Coxsackie virus B infection. Medicine (Baltimore) due to Coxsackie

8 Smith WG. Adult heart disease due to the Coxsackie virus $B$ infection. Am Heart $\mathcal{F}$ 1970;80:34-46.

9 Kitaura Y, Morita H. Secondary myocardial disease. Virus myocarditis and cardiomyopathy. $f_{p} n$ Circ $\mathcal{F}$ 1979;43: 1017-31.

10 Hayakawa $M$, Inoh $T$, Yokota $Y$, et al. A long-term followup study of acute viral and idiopathic myocarditis. Fpn Circ $₹$ 1983;47:1304-9.

11 Daly K, Richardson PJ, Olsen EG, et al. Acute myocarditis. Role of histological and virological examination in the diagnosis and assessment of immunosuppressive treatment. Br Heart $\mathcal{F}$ 1984;51:30-5.

12 Das SK, Colfer HT, Pitt B. Long-term follow-up of patients with previous myocarditis using radionuclide patients with previous myocarditis using radionucid

13 Billingham ME, Tazelaar HD. The morphological progression of viral myocarditis. Postgrad Med $\mathcal{F} 1986 ; 62$ : gression

14 Quigley PJ, Richardson PJ, Meany DT, et al. Long term follow-up in biopsy proven myocarditis: Progression to dilated cardiomyopathy. Circulation 1986;74(suppl II): 142.

15 Levi G, Scalvini S, Volterrani M, Marangoni S, Arosio G, Quadri A. Coxsackie virus heart disease: 15 years after. Eur Heart $\mathcal{f}$ 1988;9:1303-7

16 Peters NS, Poole WP. Myocarditis-a controversial disease. $\mathcal{F} R$ Soc Med 1991;84:1-2.

17 Davies MJ. The cardiomyopathies: a review of terminology, pathology and pathogenesis. Histopathology 1984; 8:363-93.

18 Parrillo JE, Cunnion RE, Epstein SE, et al. A prospective, randomized, controlled trial of prednisone for dilated randomized, controlled trial of prednisone for
cardiomyopathy. $N$ Engl $₹$ Med 1989;321:1061-8.

19 Fletcher GF, Colemen MT, Ferino PM, Marine WM, Wenger NK. Viral antibodies in patients with primary Wenger NK. Viral antibodies in patients with

20 Kawai C. Idiopathic cardiomyopathy: A study on the infection-immune theory as a cause of the disease. fap Circ F 1971;35:765-70.

21 Falase AD, Fabiya A, Odegbo-Olukoya OO. Coxsackie B viruses and heart disease in Nigerian adults. Trop Geogr Med 1979;31:237-43.

22 Cambridge G, MacArthur CG, Waterson AP, Goodwin $\mathrm{JF}$, Oakley CM. Antibodies to Coxsackie B viruses in congestive cardiomyopathy. Br Heart f 1979;41:692-6.

23 Kitaura Y. Virological study of idiopathic cardiomyopathy: serological study of virus antibodies and immunofluores- cent study of myocardial biopsies. Fpn Circ $\mathcal{F}$ 1981;45: 279-94.

24 Muir $P$, Nicholson F, Tilzey AJ, Signy M, English TA, Banatvala JE. Chronic relapsing pericarditis and dilated cardiomyopathy: serological evidence of persistent cardiomyopathy: serological evidence of

25 Torfason EG, Frisk G, Diderholm $\mathrm{H}$. Indirect and reverse radioimmunoassays and their apparent specificities in the detection of antibodies to enteroviruses in human sera. $\mathcal{F}$ Med Virol 1984;13:13-31.

26 Hufnagel G, Maisch B. Expression of MHC class I and II antigens and the II-2 receptor in rejection, myocarditis and dilated cardiomyopathy. Eur Heart $\mathcal{F}$ 1991;12(suppl D): $137-40$.

27 Kanda T, Yokoyama T, Ohshima S, et al. T-lymphocyte subsets as noninvasive markers of cardiomyopathy. Clin Cardiol 1990;13:617-22.

28 Tracy S, Wiegand V, McManus B, et al. Molecular approaches to enteroviral diagnosis in idiopathic cardiomyopathy and myocarditis. $₹ \mathrm{Am}$ Coll Cardiol 1990; 15:1688-94.

29 Ross RS, Chien KR. Of molecules and myocardium. PCR diagnosis of viral myocarditis in cardiac biopsies. Circulation 1989;82:294-5.

30 Bowles NE, Rose ML, Taylor $\mathrm{P}$, et al. End-stage dilated cardiomyopathy. Persistence of enterovirus RNA in myocardium at cardiac transplantation and lack of immune response. Circulation 1989;80:1128-36.

31 Archard LC, Bowles NE, Cunningham L, et al. Molecular probes for detection of persisting enterovirus infection of human heart and their prognostic value. Eur Heart $\mathcal{f}$ 1991;12:56-9.

32 Tracy S. A comparison of genomic homologies among the Coxsackievirus B group: use of fragments of the cloned Coxsackievirus B3 genome as probes. I Gen Virol 1985; 65:2167-72.

33 Tracy S, Chapman N, Lui H. Molecular cloning and partial characterisation of the Coxsackie B3 genome. Arch Virol characterisation

34 Wiegand V, Tracy S, Chapman N, Wucherpfennig C. Enteroviral infection in end stage dilated cardiomyopathy. Klin Wochenschr 1990;68:914-20.

35 Easton AJ, Eglin RP. The detection of Coxsackievirus RNA in cardiac tissue by in situ hybridization. $\mathcal{f}$ Gen Virol 1988;69:285-91.

36 Kandolf $\mathrm{R}$, Hofschneider $\mathrm{PH}$. Enterovirus-induced cardiomyopathy. In: Notkins AL, Oldstone MBA, eds. Concepts in viral pathogenesis III. New York: SpringerVerlag, 1989:282-90.

37 Hofschneider PH, Klingel K, Kandolf R. Toward understanding the pathogenesis of enterovirus-induced cardiomyopathy: molecular and ultrastructural cardiomyopathy: molecular and

38 Kandolf R, Hofschneider PH. Viral heart disease. Springer Semin Immunopathol 1989;11:1-13.

39 Tracy S, Chapman NM, Pistillo JM. Detection of human enteroviruses using the polymerase chain reaction. In: Becker Y, Durai G, eds. Frontiers in virology. Diagnosis of human viruses by PCR. Heidelberg: Springer-Verlag $1992 ; 331-44$

40 Jin O, Sole MJ, Butany JW, et al. Detection of Enterovirus RNA in myocardial biopsies from patients with myocarditis and cardiomyopathy using gene amplification by polymerase chain reaction. Circulation 1990;82. 8-16.

41 Weiss LM, Movahed LA, Billingham ME, Cleary ML. Detection of Coxsackievirus B3 RNA in myocardial tissues by the polymerase chain reaction. $\mathrm{Am} F \mathrm{Pathol}$ 1991;138:497-503.

42 Weiss LM, Liu XF, Chang KL, Billingham ME. Detection of enteroviral RNA in idiopathic dilated cardiomyopathy and other human cardiac tissues. $\mathcal{J}$ Clin Invest 1992;90: and oth

43 Keeling PJ, Jeffery S, Caforio ALP, et al. Similar prevalence of enteroviral genome in myocardium from patients with idiopathic dilated cardiomyopathy and controls by the polymerase chain reaction. Br Heart $\mathcal{F}$ 1992;68:554-9.

44 Petitjean J, Kopecka H, Freymuth F, et al. Detection of enteroviruses in endomyocardial biopsy by molecular approach. F Med Virol 1992;37:76-82.

45 Muir P, Nicholson F, Jhetam M, Neogi S, Banatvala JE. Rapid diagnosis of enterovirus infection by magnetic bead extraction and polymerase chain reaction detection of enterovirus RNA in clinical specimens. $f$ Clin Microbiol 1993;31:31-8.

46 Liljeqvist JA, Bergstrom T, Holmstrom S, et al. Failure to demonstrate enterovirus aetiology in Swedish to demonstrate enterovirus aetiology in Swedish patients with

47 Grasso M, Arbustini E, Silini E, et al. Search for coxsackievirus B3 RNA in idiopathic dilated cardiomyopathy using gene amplification by polymerase chain reaction. Am $\mathcal{F}$ Cardiol 1992;69:658-64.

48 Racaniello V. Poliovirus neurovirulence. Adv Virus Res 1988;34:217-46.

49 Tracy S, Chapman NM, Beck M. Molecular biology and pathogenesis of Coxsackie B viruses. Rev Med Virol 1991;1:145-54.

50 Tracy S, Hufnagel G, Chapman NM. Interesting problems in enteroviral inflammatory heart disease. Herz 1992;17:79-84. 